\title{
The Role of Transoral Robotic Surgery in the Management of Oropharyngeal Cancer: A Review of the Literature
}

\author{
Samuel A. Dowthwaite, ${ }^{1}$ Jason H. Franklin, ${ }^{1}$ David A. Palma, ${ }^{2}$ Kevin Fung, \\ John Yoo, ${ }^{1}$ and Anthony C. Nichols ${ }^{1,3}$ \\ ${ }^{1}$ Department of Otolaryngology-Head and Neck Surgery, The University of Western ON, London, ON, Canada N6A 3K7 \\ ${ }^{2}$ Department of Radiation Oncology, The University of Western Ontario, London, Ontario, Canada N6A 3K7 \\ ${ }^{3}$ Victoria Hospital, London Health Science Centre, Department of Otolaryngology-Head and Neck Surgery, Room B3-438A, \\ 800 Commissioners Road East London, ON, Canada N6A 5W9
}

Correspondence should be addressed to Anthony C. Nichols, anthony.nichols@lhsc.on.ca

Received 18 January 2012; Accepted 13 February 2012

Academic Editors: J. Bentel and O. Hansen

Copyright (C 2012 Samuel A. Dowthwaite et al. This is an open access article distributed under the Creative Commons Attribution License, which permits unrestricted use, distribution, and reproduction in any medium, provided the original work is properly cited.

\begin{abstract}
Background. Transoral robotic surgery (TORS) is an emerging treatment option for the treatment of head and neck malignancies, particularly for oropharyngeal squamous cell carcinoma (OPSCC). Preliminary studies have demonstrated excellent oncologic and functional outcomes that have led to a resurgence of interest in the primary surgical management of OPSCC. The aim of the present study was to review the evidence base supporting the use of TORS in OPSCC. Methods. Studies evaluating the application of TORS in the treatment of head and neck squamous cell carcinoma (HNSCC), and more specifically OPSCC, were identified for review. Further searches were made of reference lists for complete evaluation of minimally invasive surgery (MIS) in treating OPSCC. Results. Seventeen results relating to the application of TORS in treatment of OPSCC were identified. Further results relating to the role of transoral laser microsurgery (TLM) in OPSCC were included for review. Feasibility, oncologic, and functional data is summarized and discussed. Discussion. Management strategies for patients with OPSCC continue to evolve. Minimally invasive surgical techniques including TORS and TLM offer impressive functional and oncologic outcomes particularly for patients with early T-classification and low-volume regional metastatic disease. Potential exists for treatment deintensification, particularly in patients who are HPV positive.
\end{abstract}

\section{Introduction}

Approximately 500,000 new cases of head and neck squamous cell carcinoma (HNSCC) are diagnosed each year making HNSCC the 6th most common cancer worldwide [1]. The rate of HNSCC has been increasing recently secondary to an epidemic of human papillomavirus- (HPV-) related oropharyngeal squamous cell cancer (OPSCC).

These trends, which have seen rates of OPSCC as much as double over the last three decades in some countries, have been associated with a shift in demographics to a younger population that is typically high functioning with lower rates of comorbid illness [2]. Combined with lower rates of smoking and alcohol abuse and an intrinsic improved response rate of HPV-related OPSCC to curative treatment regimens, the overall and disease-free survival rates in this patient group are significantly higher than previously observed. As such, long-term quality of life considerations have been made even more relevant to the multidisciplinary team coordinating the care of these patients.

These new developments in the pathogenesis of HNSCC, and in particular OPSCC, are occurring in the context of large-scale paradigm shifts over the past two decades towards organ preservation treatment protocols. The Veterans Affairs laryngeal cancer study published in 1991 began the era of organ preservation and led to the application of primary radiation approaches to other subsites such as the oropharynx [3]. Although a randomized controlled trial of primary radiation versus surgery for oropharyngeal cancer has not been carried out, several retrospective analyses have demonstrated less major complications and improved functional outcomes with radiation compared to traditional primary 
surgical approaches. These results have contributed to the widespread adoption of primary nonsurgical treatment in patients with OPSCC.

Minimally invasive surgery (MIS) for HNSCC continues to be extensively reported within the head and neck literature, driven by the desire to offer a less morbid alternative to chemoradiation. These techniques have included transoral laser microsurgery (TLM) and more recently, transoral robotic surgery (TORS). TORS was first introduced into the literature by Weinstein et al. in 2005 with their case report of a supraglottic laryngectomy performed in a canine model [4]. The adaptation of this preexisting robotic technology to a new clinical application provided a watershed moment in the evolution of treatment options for the surgical management of head and neck aerodigestive tract pathology.

Since this early report, the development of TORS in its various human applications has been steadily progressing with feasibility studies confirming the safety and usability of this technology in live human patients $[5,6]$. Given the benefit of infield optics provided by the robot-mounted double video endoscope, line-of-sight issues associated with more traditional transoral techniques are overcome with the use of TORS. This factor, combined with the valuable 3-dimensional imagery, tremor filtration and the resultant precision movements translated from the console to the robotic instruments at the operative site, allow for accurate dissection of tissue planes in a way not previously possible.

Various reports of the use of TORS in benign disease processes have been published in the literature [7-10], however, the majority of reports have concentrated on the application of TORS in patients with mucosal malignancies, particularly of the larynx and oropharynx [11-14]. Emerging evidence suggests that effective primary surgical management of these malignancies may provide an opportunity for deintensification of adjuvant treatments with resultant improvements in patient's posttreatment quality of life, without compromising oncologic outcomes.

The aim of the current review is to provide an evaluation of the existing literature with regards to the oncologic and functional outcomes following treatment of OPSCC with minimally invasive surgery and in particular, TORS.

\section{Methods}

A literature search was conducted using PUBMED and MEDLINE with search parameters including (transoral[Title] AND (("robotics"[MeSH Terms] OR "robotics"[All Fields] OR "robotic"[All Fields]) OR robot[All Fields] OR telerobot[All Fields] OR ("robotics"[MeSH Terms] OR "robotics"[All Fields] OR "telerobotics"[All Fields]) OR robot-assisted[Title])) OR TORS[Title].

The references of the identified studies were reviewed further for completeness. In addition, studies relating to the use of TLM were identified to facilitate a complete evaluation of the evidence base for the current role of MIS in the management of OPSCC.

Only those studies dealing specifically with the management of patients with HNSCC were included, with descrip- tions of TORS for benign disease, nonmucosal malignancies of the upper aerodigestive tract, novel applications of TORS and descriptions of cadaveric studies all being excluded. Specifically, data relating to the evaluation of quality of life, oncologic and functional outcomes in the identified studies was reviewed.

\section{Results}

Sixty-nine results were identified for review of which the references were further evaluated for potential inclusion in the analysis. Of particular note, studies related to the use of transoral laser microsurgery were included for complete review of minimally invasive surgery in the treatment of OPSCC.

Sixteen studies were excluded as they were not related to the application of TORS in patients with HNSCC. Forty studies addressed the role of TORS in treatment of head and neck tumors and in particular, 17 studies commented directly on the use of TORS in patients with OPSCC. Six studies were identified that investigated quality of life and functional outcomes following TORS for treatment of HNSCC/OPSCC with a further seven discussing feasibility aspects including setup and operative times (Table 1).

3.1. Feasibility. The initiation of new TORS programs, generally established in conjunction with robotic programs in other surgical specialties, has repeatedly demonstrated success in establishing safe and efficient robotic services for head and neck oncology units [15-19]. Operative setup times have been reported to take between 2 minutes and 140 minutes. Generally, average setup times after preliminary experience within the TORS team are under 30 minutes. Further demonstration of the increased efficiency following the introduction of TORS to a department is documented in the data from Moore et al. who significantly improved the setup time after their initial experience, suggesting that the learning curve for operative efficiency is complete after approximately 10 patients [14]. The average operative time across all 7 studies is just under 75 minutes.

For patients who require free flap reconstruction of the ablative defect, feasibility studies and initial case series detailing free tissue transfers via minimally invasive surgical approaches and robotic-assisted microanastomotic techniques have also demonstrated reliable perioperative outcomes [17, 20-25].

3.2. Oncologic Outcomes. In excess of 500 patients receiving TORS to manage OPSCC have been reported across 17 studies. A summary of the TORS literature relating to the oncologic outcomes in patients with OPSCC is presented in Table 2. Generally, these studies are retrospective in nature and report on highly selected patients. Many reflect treatment of advanced stage disease by virtue of N-positivity with associated early T-classification: several trials report only on the treatment of T1-2 lesions with various stages of cervical disease $[12,16,26,27]$. These factors make 
TABLE 1: Setup and operative times for TORS.

\begin{tabular}{|c|c|c|}
\hline Study & Complete setup time (minutes) & Operative time (minutes) \\
\hline \multirow[t]{2}{*}{ O’Malley et al. [12] (3 patients) } & Ave -44 & Ave -105 \\
\hline & Range- $-38-52$ & Range-91-131 \\
\hline \multirow[t]{2}{*}{ Weinstein et al. [11] (27 patients) } & Ave -9 & Ave -103 \\
\hline & Range-2-22 & Range-26-233 \\
\hline \multirow[t]{2}{*}{ Genden et al. [16] (18 patients) } & Ave - 55 & Ave - 84 \\
\hline & Range-20-140 & Range-45-150 \\
\hline \multirow[t]{2}{*}{ Park et al. [27] (5 patients) } & Ave -19 & Ave -44 \\
\hline & Range-15-25 & Range- $40-50$ \\
\hline \multirow[t]{4}{*}{ Moore et al. [14] (45 patients) } & Ave 1st 10-69 & Ave- -72 \\
\hline & Range- $-54-59$ & Range- $-45-320$ \\
\hline & Ave 2nd 35-22 & Ave-71 \\
\hline & Range-14-28 & Range-6-309 \\
\hline \multirow[t]{2}{*}{ Lawson et al. [19] (24 patients) } & Ave- -24 & Ave- -67 \\
\hline & Range- $-10-60$ & Range- $-12-180$ \\
\hline \multirow[t]{2}{*}{ Aubry et al. [15] (17 patients) } & Ave -21 Range $-10-50$ & Ave -40 \\
\hline & & Range- $-10-90$ \\
\hline
\end{tabular}

generalizations and direct comparisons to the nonsurgical literature difficult.

Nonetheless, preliminary data relating to local control, disease-specific survival, and overall survival using upfront TORS is encouraging, with early overall survival rates at 1 year exceeding $90 \%$ with emerging 2 -year survival data between $80 \%$ and $90 \%[13,20,28,29]$. Cohen et al. reported 1 and 2 year overall survival rates among a 50 patient cohort of $95.7 \%$ and $80.6 \%$, respectively. Thirty-nine patients had T1/T2 lesions (78\%), 8 had T3 lesions (16\%), and 3 had T4 lesions $(6 \%)$, with this low primary tumor volume further demonstrated by the fact that only a single free tissue transfer was required for reconstruction of the ablative defect [13]. Ongoing efforts at other institutions have replicated these early survival results, with Genden et al. demonstrating an overall survival of $90 \%$ amongst their cohort of 30 patients treated with primary TORS for HNSCC, whilst White et al. recorded a $86.5 \% 2$ year overall survival for 71 patients undergoing TORS as part of treatment for HNSCC of all subsites ( $87 \%$ patients had OPSCC) [20, 29]. In both of these studies, a majority of patients again had advanced stage disease with early T-stage status and small volume nodal disease.

These oncologic outcomes with TORS largely mirror the experience reported in the TLM literature with patient populations again largely demonstrating early T-classification, deintensified adjuvant treatment recommendations based on pathological staging, and impressive oncologic control (Table 3). Steiner was one of the first to report on this in 2003 with a report on 48 patients treated for mostly advanced stage OPSCC involving the base of the tongue demonstrating a local control rate over 5 years of $85 \%$ [30]. Most recently, Haughey et al. have published multicenter data on 204 patients treated with TLM \pm adjuvant therapy for advanced stage OPSCC, with 2 and 5 year overall survival rates of $89 \%$ and 78\%, respectively, and a local control of $97 \%$ [31]. Adjuvant treatment was avoided in $26 \%$, with the remaining 150 patients receiving adjuvant treatment of which 33 required chemoradiotherapy. Although adjuvant radiotherapy was associated with improved overall survival, the addition of chemotherapy did not significantly impact on survival.

This potential to deintensify treatment based on successful surgical control of the primary tumor burden has led to retrospective analysis of the experience in some centers with single modality treatment of OPSCC. Grant et al. reported in 2009 their experience with 69 patients with select mostly early T-stage OPSCC who did not receive adjuvant therapy (64\% not indicated and 36\% offered but declined) [32]. The 5-year overall survival rate was $86 \%$ with no patients requiring either tracheostomy of gastrostomy tube.

3.3. Functional Outcomes. It remains unclear whether a subset of patients with OPSCC can be treated with primary surgery in order to achieve superior functional results with deintensification of adjuvant treatment. Following on from Steiner's early work the use of TLM has repeatedly demonstrated impressive functional outcomes with low rates of gastrostomy dependency, decannulation and high quality of life scores on questionnaire assessment. These results are summarized in Tables 3 and 4.

Early TORS data supports these impressive functional outcomes with most series reporting 1-year gastrostomytube rates under $10 \%$ and long-term rates of $0 \%$ for patients treated with upfront surgery $[14,20,28,33]$ (Table 5). Higher rates of gastrostomy tube dependency have been reported in TORS case series including all HNSCC subsites with typically higher swallowing dysfunction observed in patients with laryngeal malignancies $[1,2]$. 
TABLE 2: Oncologic outcomes following TORS for OPSCC.

\begin{tabular}{|c|c|c|c|c|c|c|}
\hline Study & $\begin{array}{c}\text { Number of } \\
\text { cases }\end{array}$ & Primary site & $\begin{array}{l}\text { Pathological } \\
\text { stage }\end{array}$ & HPV status & $\begin{array}{l}\text { Followup period } \\
\text { (mean) }\end{array}$ & Oncologic outcomes \\
\hline \multirow[t]{9}{*}{ Cohen et al. [13] (Ap r'10) } & 50 & Oropharynx & $\mathrm{T} 1 / 2: 39$ & HPV-neg: 13 & $\begin{array}{l}\text { HPV-neg: } \\
23.0 \text { mths }\end{array}$ & 1 yr: $95.7 \%(45 / 47)$ \\
\hline & & & T3: 11 & & & 2 yr: $80.6 \%(25 / 31)$ \\
\hline & & & & HPV-pos: 37 & $\begin{array}{l}\text { HPV-pos: } \\
24.8 \text { mths }\end{array}$ & \\
\hline & & & N0: 9 & & & \\
\hline & & & $\mathrm{N} 1: 21$ & & & \\
\hline & & & N2a: 0 & & & \\
\hline & & & N2b: 20 & & & \\
\hline & & & N2c: 0 & & & \\
\hline & & & N3: 0 & & & \\
\hline \multirow[t]{8}{*}{ Genden et al. [20] (Aug'11) } & 30 & $\begin{array}{c}27 \text { oropharynx } \\
(90 \%)\end{array}$ & $\mathrm{T} 1 / 2: 30 / 30$ & N/A & $20.4 \mathrm{mths}$ & 18 mth: \\
\hline & & 1 larynx $(3.3 \%)$ & & & & $\begin{array}{c}\text { locoregional control: } \\
91 \%\end{array}$ \\
\hline & & $\begin{array}{c}1 \text { oral cavity } \\
(3.3 \%)\end{array}$ & N0: 6 & & & distant control: $93 \%$ \\
\hline & & $\begin{array}{c}1 \text { hypopharynx } \\
(3.3 \%)\end{array}$ & N1: 10 & & & DFS: $78 \%$ \\
\hline & & & N2a: 5 & & & OS: $90 \%$ \\
\hline & & & N2b: 7 & & & \\
\hline & & & N2c: 2 & & & \\
\hline & & & N3: 0 & & & \\
\hline \multirow[t]{9}{*}{ Weinstein et al. [28] (Nov'10) } & 47 & Oropharynx & T1/2: 36 & N/A & 26 mths & Overall: \\
\hline & & & $\mathrm{T} 3 / 4: 11$ & & & 1 yr: $96 \%(45 / 47)$ \\
\hline & & & & & & 2 yr: $82 \%(27 / 33)$ \\
\hline & & & N0: 1 & & & DFS: \\
\hline & & & N1: 24 & & & 1 yr: 96\% (45/47) \\
\hline & & & N2a: 1 & & & 2 yr: $79 \%(26 / 33)$ \\
\hline & & & N2b: 19 & & & \\
\hline & & & N2c: 2 & & & \\
\hline & & & N3: 0 & & & \\
\hline \multirow[t]{9}{*}{ White et al. [29] (Dec'10) } & 89 & $\begin{array}{c}77 \text { oropharynx } \\
(87 \%)\end{array}$ & $\mathrm{T} 1 / 2: 71$ & N/A & $\begin{array}{l}26 \text { mths } \\
\text { (median) }\end{array}$ & DFS (entire cohort) \\
\hline & & 10 larynx $(11 \%)$ & Т3/4: 18 & & & 2 years: $86.3 \%$ \\
\hline & & $\begin{array}{c}2 \text { oral cavity } \\
(2 \%)\end{array}$ & & & & \\
\hline & & & N0: 27 & & & $\begin{array}{c}\text { DFS (primary TORS } \\
\text { cohort) }\end{array}$ \\
\hline & & & N1: 8 & & & 2 years: $89.3 \%$ \\
\hline & & & N2a: 11 & & & \\
\hline & & & N2b: 26 & & & \\
\hline & & & $\mathrm{N} 2 \mathrm{c}: 12$ & & & \\
\hline & & & N3: 4 & & & \\
\hline
\end{tabular}

3.4. The Role of HPV. A further confounder in the management of OPSCC is the role of HPV in disease pathogenesis and significance as a prognostic factor, apparently irrespective of treatment modality $[13,34-36]$. The exact incidence of HPV infection and its impact on patients with OPSCC is still being elucidated in prospective trials after having initially been appreciated in retrospective studies. Ang et al. published their experience in the treatment of 323 patients 


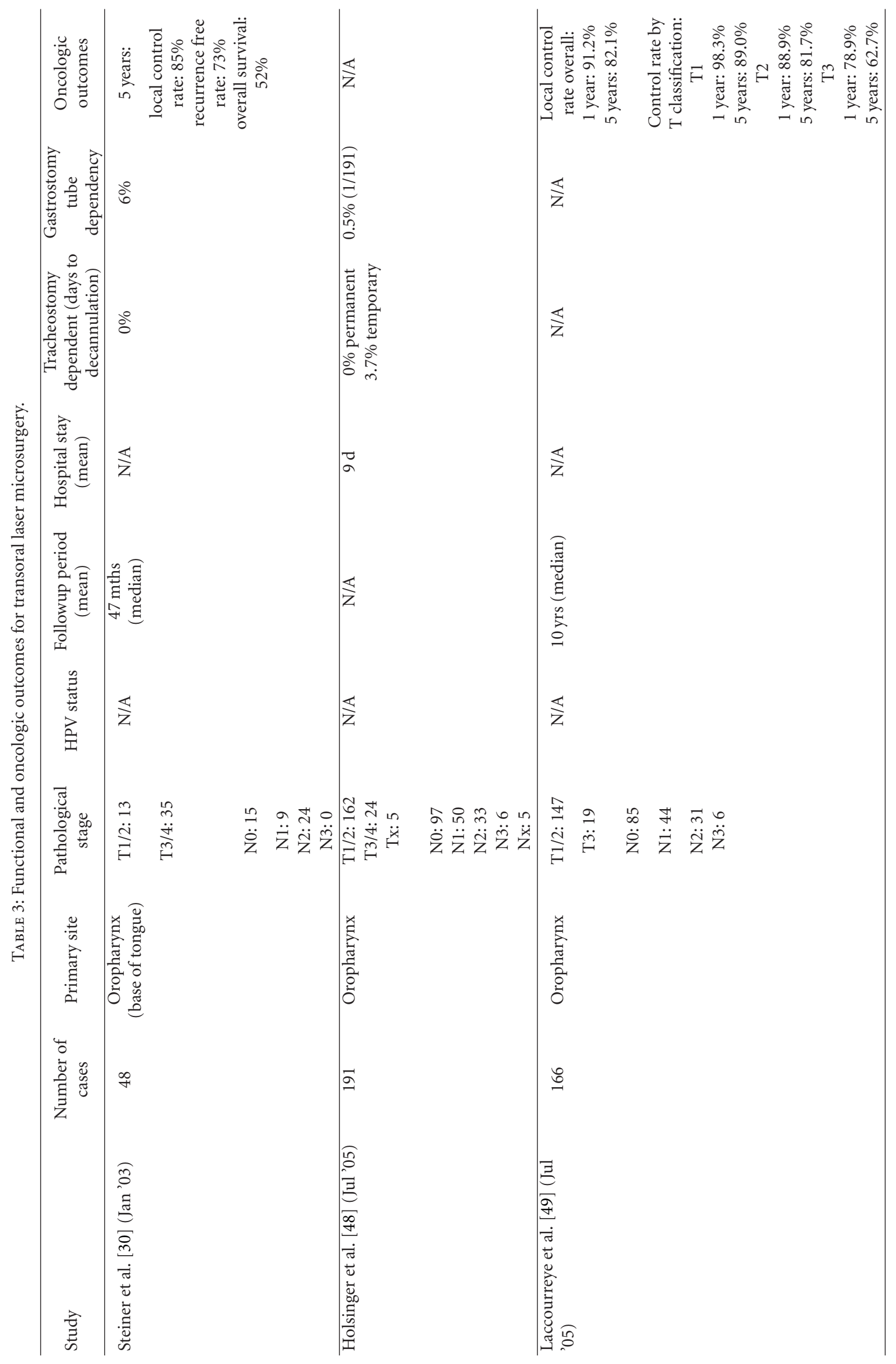




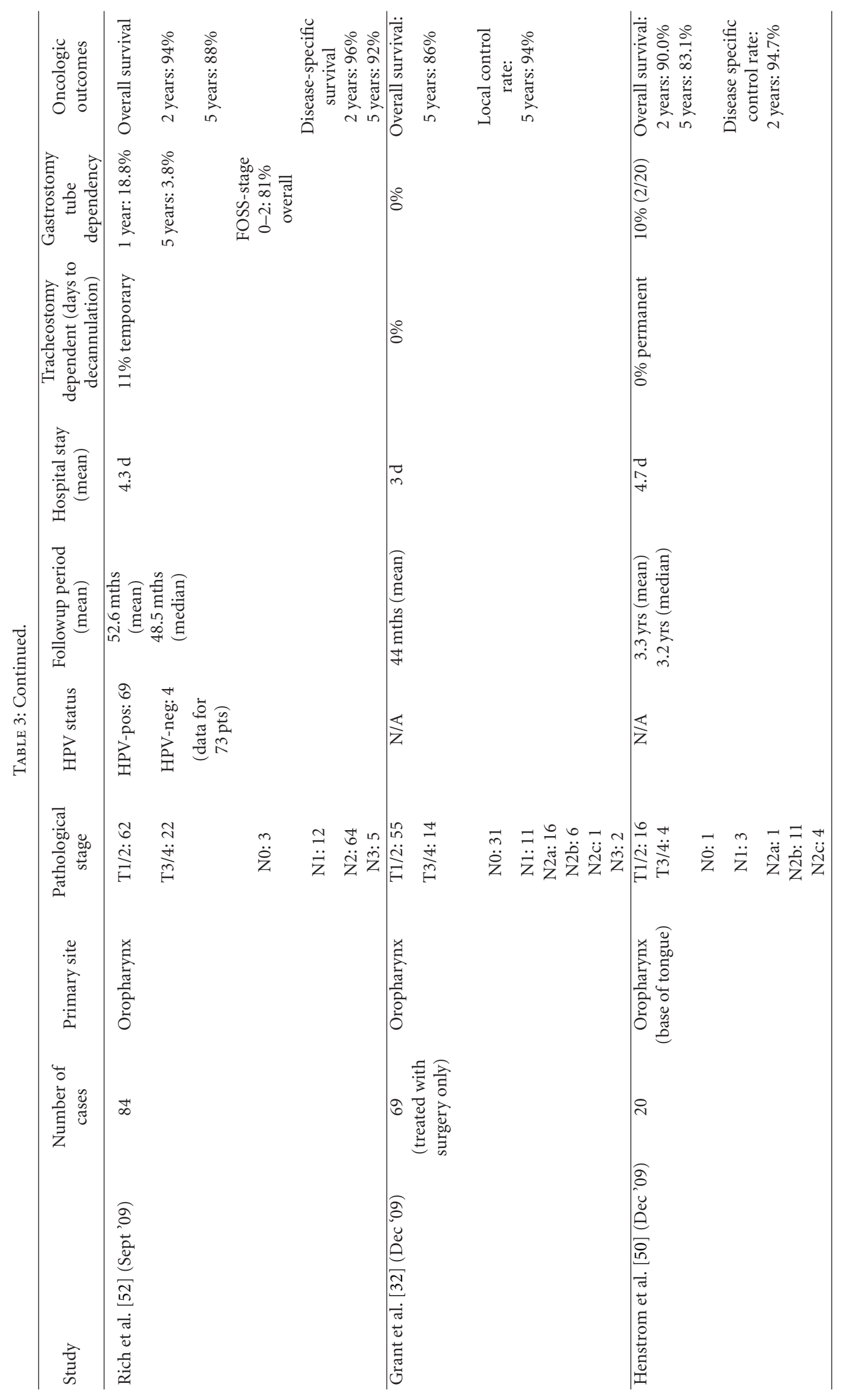




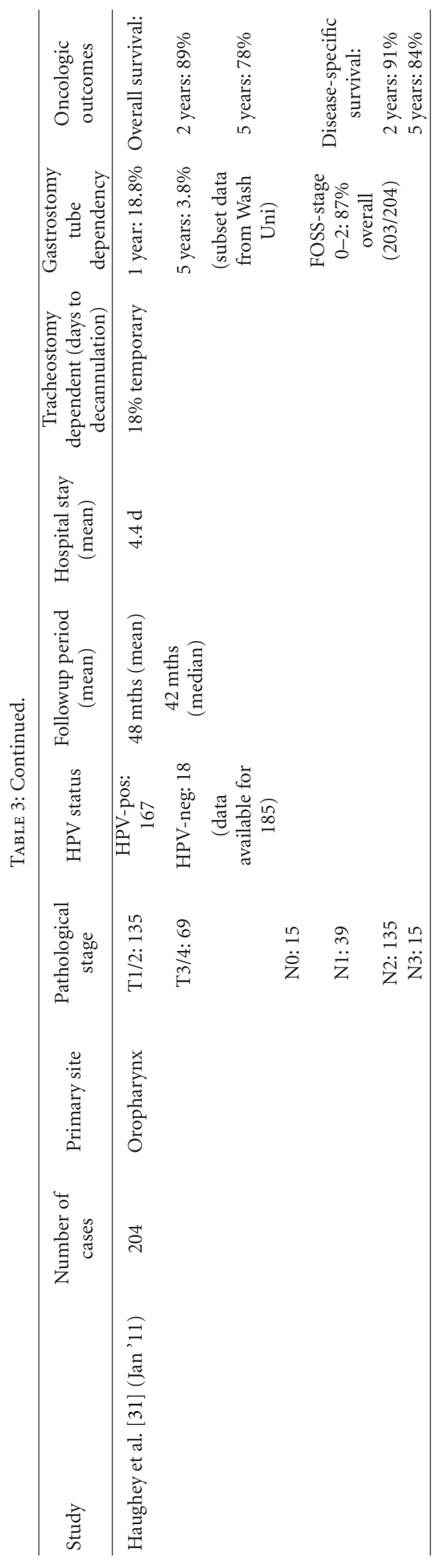


TABLE 4: Gastrostomy tube dependency rates following TORSlong and short term.

\begin{tabular}{lccc}
\hline Study & Short term & 1 Year & 2 Years \\
\hline Weinstein et al. [28] (2010) & & $2.40 \%$ & $0 \%$ \\
Moore et al. [14] (2009) & $18 \%$ & $0 \%$ & $0 \%$ \\
Iseli et al. [33] (2009) & & $9.50 \%$ & \\
Genden et al. [20] (2011) & & $0 \%$ & $0 \%$ \\
\hline
\end{tabular}

with locally advanced OPSCC [37]. The HPV-positive rate was $63.8 \%$ (206/323); HPV-positivity was associated with a significant relative reduction in the risk of death of $58 \%$, translating to an $82.4 \%$ survival rate at 3 years compared to $57.1 \%$ in those patients HPV-negative. This significant survival advantage was also demonstrated Nichols et al. in 2010 reporting on 68 patients with OPSCC, of whom 53 were found to be HPV-positive (78\%) [38]. Patients who were $\mathrm{HPV}$-positive were 5 times less likely to develop recurrence and $60 \%$ less likely to die of disease when compared to their HPV-negative counterparts.

Weinstein et al. also reported on 50 patients treated for OPSCC with an HPV-positive rate of 74\% (37/50). In this series of patients treated with upfront TORS, the diseasespecific survival of patients with HPV-positive OPSCC at 1year and 2 -years was $97 \%$ and $90 \%$, respectively. However, the HPV-negative cohort in this primary surgical series demonstrated equal oncologic control with disease-specific survival rates at both 1 -year and 2-years of $100 \%$.

\section{Discussion}

The management of patients with OPSCC continues to evolve with both advances in therapeutic regimens and evolution of our understanding of the underlying disease pathophysiology. Early surgery-based treatment paradigms have been largely abandoned with the general adoption of nonsurgical regimens supported by an evidence base demonstrating superior functional outcomes whilst retaining comparable survival results [39-41].

Paralleling the improvements in surgical technique, the natural evolution of radiotherapy has resulted in a decrease in treatment-related morbidity. Refinement of targeted 3D conformal radiotherapy methods such as intensitymodulated radiotherapy (IMRT) has allowed increased precision in delivery of radiotherapy to patients with HNSCC with associated decreases in adverse sequelae [42]. Tempering these benefits, however, has effects related to escalation of treatments in an effort to improve survival outcomes. Meta-analysis data have demonstrated improved survival with altered fractionated regimens and/or the addition of chemotherapy, at the expense of significant increases in treatment related toxicities, particularly acute mucositis and long-term swallowing dysfunction [43-46].

As the etiologic factors involved in the development of OPSCC continue to be elucidated one variable that has proven immensely significant is the role of human papillomavirus (HPV). This HPV epidemic has interestingly occurred during the same period as the widespread adoption of chemoradiotherapy as standard of care treatment for advanced stage OPSCC. This has managed to blur the lines somewhat with respect to whether these improved outcomes are secondary to treatment modifications or reflective of a naturally improved survival rate in patients with HPVpositive disease. Furthermore, the HPV-positive OPSCC patient has been defined as typically younger with lower rates of significant medical comorbidities [47]. Combined with improved rates of cure this young, high functioning population requires special consideration given that any treatment related side effects may need to be lived with for extended periods of time.

Oncologic outcomes in patients with HPV-positive OPSCC remain similar regardless of treatment approach. Therefore, an appreciation of functional outcomes represents a significant and fundamental consideration when formulating management recommendations. Transfacial and transmandibular surgical approaches to the oropharynx carry potential morbidity and have been demonstrated on retrospective analysis to be associated with poor functional outcomes when compared to radiotherapy [39-41]. Both TLM and TORS facilitate surgical access to the lower subsites of the upper aerodigestive tract without need for traditional methods requiring open surgical approaches. Repeatedly, these MIS techniques have both demonstrated sound oncologic and functional/quality of life outcomes [14, 28, 4852]. Potential benefits also exist with respect to adjuvant treatment deintensification and avoidance altogether in select circumstances [32, 53-55].

Comparisons of outcomes after TORS versus chemoradiotherapy across studies are hampered by differences in baseline patient populations, selection, and treatment technique. Nonetheless, rates of gastrostomy tube dependency after chemoradiotherapy have typically been reported as between $9 \%$ to $39 \%$ in patients treated with chemoradiotherapy [56-59]. Critical analysis of the chemoradiotherapy literature reveals a patient population that typically differs from the recent MIS literature with inclusion of patients with unresectable (T4b) and/or bulky primary disease (greater than $4 \mathrm{~cm}$ ), and typical exclusion of early primary disease such as in the series reported by the Radiation Therapy Oncology Group [37]. Therefore, direct comparisons across these reported functional outcomes are difficult.

The promising impact of TORS on the quality of life and survival outcomes of OPSCC patients remains an important clinical question that requires higher levels of supporting evidence. A recent surgical consensus statement (the "IDEAL" guidelines) suggests that randomized comparisons be carried out wherever possible, once adequate pretrial data are available [60]. Through centres in London and Ottawa, Ontario, the ORATOR Study (Oropharyngeal cancer Radiation versus TORS) is planned to open in early 2012. This study will randomize OPSCC patients to curative intent treatment with either upfront TORS \pm adjuvant treatment versus nonsurgical treatment, with the primary endpoint being superior swallowing function at one year in the TORS arm as determined by the MD Anderson Dysphagia Inventory (MDADI). 


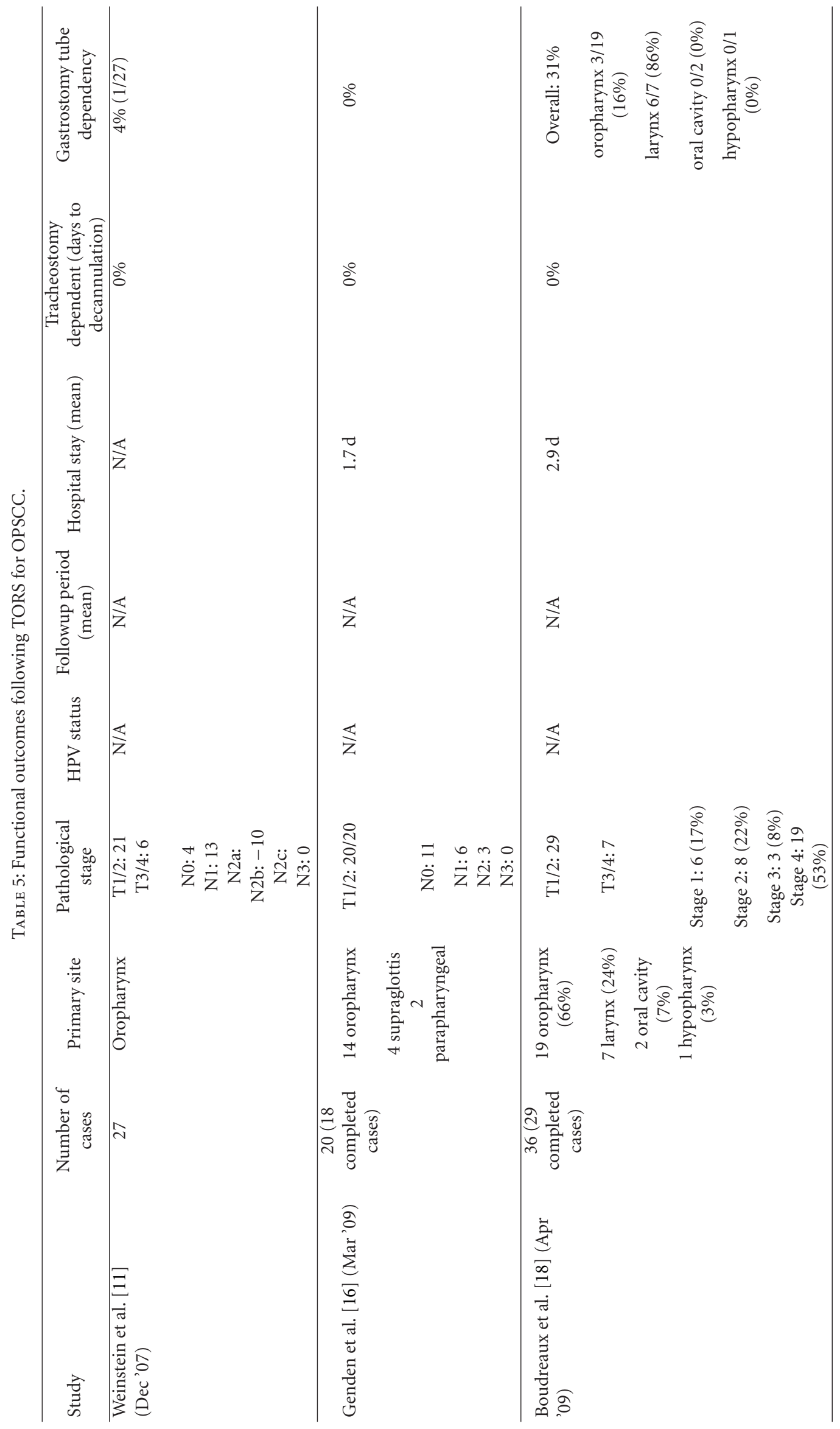




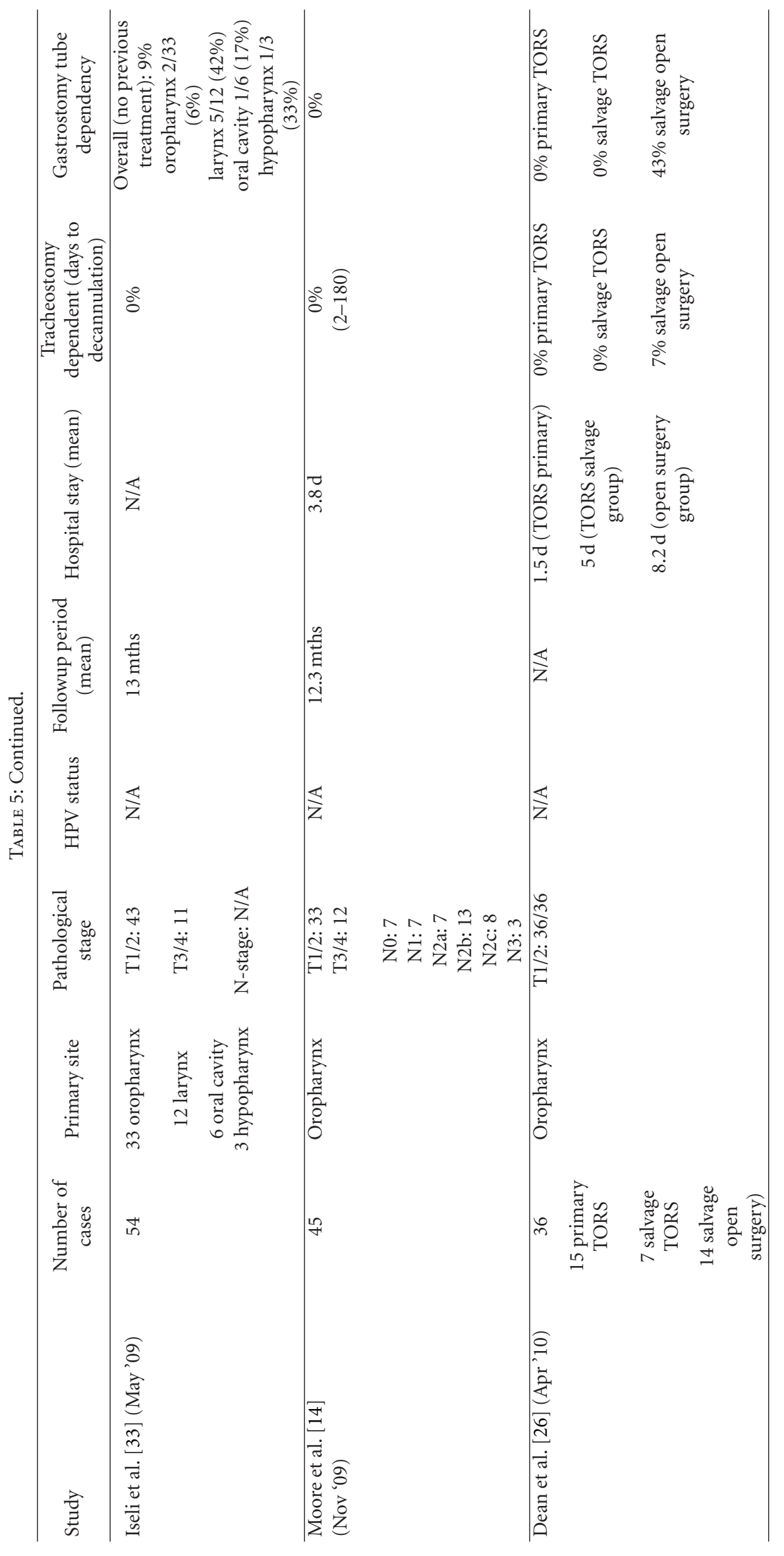




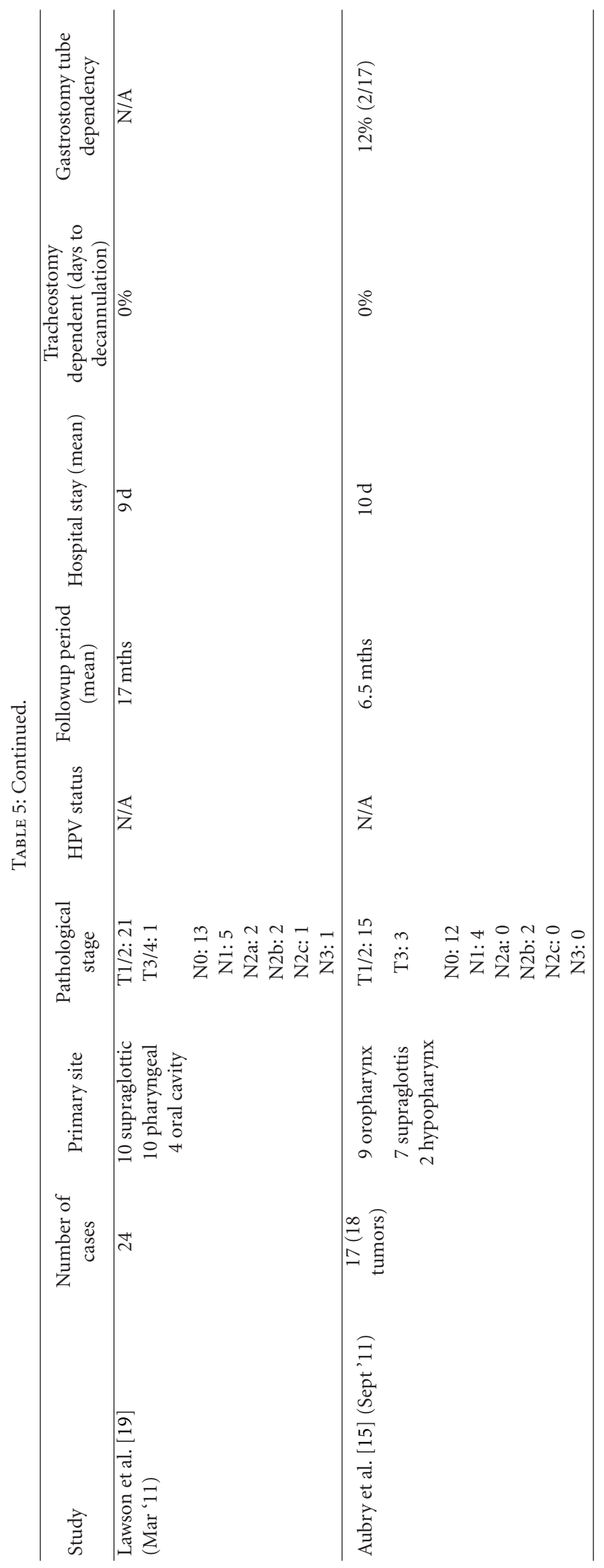


Ultimately, ORATOR aims to assist in the identification of OPSCC patients who might be best served by upfront surgery. Adapting data from other head and neck subsites we understand that in a select group of "surgical responders" chemoradiotherapy represents a suboptimal treatment approach due to either lack of response in locoregional disease control or excessive treatment-related side effects and morbidity. Further, defining the "surgical responder" in patients with OPSCC is perhaps even more important than other subsites such as the larynx given the relative lack of success with surgical salvage. Combined with the work of others, ORATOR can hopefully work to identify the ideal OPSCC patients for upfront TORS, with the realization that chemoradiotherapy will still represent an excellent treatment option for the "nonsurgical responder."

Ultimately, providing truly accurate risk assessment will require a clearer understanding of the underlying molecular genetics of HNSCC. Only then can patients be risk stratified with relative certainty utilizing both clinical and genetic evidence to guide treatment plans. Recent highthroughput genetic sequencing publications in science by Agrawal and Stransky provide exciting insights into a future that promises genetically guided management to optimize survival and minimize treatment-related morbidity [61, 62]. Further, current vaccination programs aimed at reducing HPV transmission within the wider community provide an exciting opportunity to impact significantly on the incidence of OPSCC.

\section{Conclusion}

The continued development of minimally invasive surgical techniques such as TORS offers a significant opportunity to impact positively on patient quality of life and posttreatment function whilst retaining satisfactory oncologic control. Initial feasibility and case series reports are encouraging but require further validation through well-designed randomized control trials prior to widespread shifts in accepted treatment paradigms.

\section{References}

[1] J. Ferlay, H. R. Shin, F. Bray, D. Forman, C. Mathers, and D. M. Parkin, "Estimates of worldwide burden of cancer in 2008: GLOBOCAN 2008," International Journal of Cancer, vol. 127, no. 12, pp. 2893-2917, 2010.

[2] A. Näsman, P. Attner, L. Hammarstedt et al., "Incidence of human papillomavirus (HPV) positive tonsillar carcinoma in Stockholm, Sweden: an epidemic of viral-induced carcinoma?" International Journal of Cancer, vol. 125, no. 2, pp. 362-366, 2009.

[3] The Department of Veterans Affairs Laryngeal Cancer Study Group, "Induction chemotherapy plus radiation compared with surgery plus radiation in patients with advanced laryngeal cancer," New England Journal of Medicine, vol. 324, no. 24, pp. 1685-1690, 1991.

[4] G. S. Weinstein, B. W. O'Malley, and N. G. Hockstein, "Transoral robotic surgery: supraglottic laryngectomy in a canine model," Laryngoscope, vol. 115, no. 7, pp. 1315-1319, 2005.
[5] N. G. Hockstein, B. W. O’Malley, and G. S. Weinstein, "Assessment of intraoperative safety in transoral robotic surgery," Laryngoscope, vol. 116, no. 2, pp. 165-168, 2006.

[6] N. G. Hockstein, G. S. Weinstein, and B. W. O’Malley, "Maintenance of hemostasis in transoral robotic surgery," $O R L$, vol. 67, no. 4, pp. 220-224, 2005.

[7] C. Vicini, I. Dallan, P. Canzi et al., "Transoral robotic surgery of the tongue base in obstructive sleep apnea-hypopnea syndrome: anatomic considerations and clinical experience," Head and Neck, vol. 34, no. 1, pp. 15-22, 2012.

[8] C. Vicini, I. Dallan, P. Canzi, S. Frassineti, M. G. La Pietra, and F. Montevecchi, "Transoral robotic tongue base resection in obstructive sleep apnoea-hypopnoea syndrome: a preliminary report," ORL, vol. 72, no. 1, pp. 22-27, 2010.

[9] R. R. Walvekar, G. Peters, E. Hardy et al., "Robotic-assisted transoral removal of a bilateral floor of mouth ranulas," World Journal of Surgical Oncology, vol. 9, p. 78, 2011.

[10] R. R. Walvekar, P. D. Tyler, N. Tammareddi, and G. Peters, "Robotic-assisted transoral removal of a submandibular megalith," Laryngoscope, vol. 121, no. 3, pp. 534-537, 2011.

[11] G. S. Weinstein, B. W. O'Malley, W. Snyder, E. Sherman, and H. Quon, "Transoral robotic surgery: radical tonsillectomy," Archives of Otolaryngology-Head and Neck Surgery, vol. 133, no. 12, pp. 1220-1226, 2007.

[12] B. W. O’Malley, G. S. Weinstein, W. Snyder, and N. G. Hockstein, "Transoral robotic surgery (TORS) for base of tongue neoplasms," Laryngoscope, vol. 116, no. 8, pp. 1465-1472, 2006.

[13] M. A. Cohen, G. S. Weinstein, B. W. O’Malley Jr, M. Feldman, and H. Quon, "Transoral robotic surgery and human papillomavirus status: oncologic results," Head and Neck, vol. 33, no. 4, pp. 573-580, 2011.

[14] E. J. Moore, K. D. Olsen, and J. L. Kasperbauer, "Transoral robotic surgery for oropharyngeal squamous cell carcinoma: a prospective study of feasibility and functional outcomes," Laryngoscope, vol. 119, no. 11, pp. 2156-2164, 2009.

[15] K. Aubry, M. Yachine, A.-F. Perez et al., "Transoral robotic surgery for head and neck cancer: a series of 17 cases," European Annals of Otorhinolaryngology, Head and Neck Diseases, vol. 128, no. 6, pp. 290-296, 2011.

[16] E. M. Genden, S. Desai, and C. K. Sung, "Transoral robotic surgery for the management of head and neck cancer: a preliminary experience," Head and Neck, vol. 31, no. 3, pp. 283289, 2009.

[17] V. K. Mukhija, C.-K. Sung, S. C. Desai, G. Wanna, and E. M. Genden, "Transoral robotic assisted free flap reconstruction," Otolaryngology-Head and Neck Surgery, vol. 140, no. 1, pp. 124-125, 2009.

[18] B. A. Boudreaux, E. L. Rosenthal, J. S. Magnuson et al., "Robot-assisted surgery for upper aerodigestive tract neoplasms," Archives of Otolaryngology-Head and Neck Surgery, vol. 135, no. 4, pp. 397-401, 2009.

[19] G. Lawson, N. Matar, M. Remacle, J. Jamart, and V. Bachy, "Transoral robotic surgery for the management of head and neck tumors: learning curve," European Archives of Oto-RhinoLaryngology, vol. 268, no. 12, pp. 1795-1801, 2011.

[20] E. M. Genden, T. Kotz, C. C. L. Tong et al., "Transoral robotic resection and reconstruction for head and neck cancer," $L a-$ ryngoscope, vol. 121, no. 8, pp. 1668-1674, 2011.

[21] J. C. Selber, G. Robb, J. M. Serletti, G. Weinstein, R. Weber, and F. C. Holsinger, "Transoral robotic free flap reconstruction of oropharyngeal defects: a preclinical investigation," Plastic and Reconstructive Surgery, vol. 125, no. 3, pp. 896-900, 2010. 
[22] J. C. Selber, "Transoral robotic reconstruction of oropharyngeal defects: a case series," Plastic and Reconstructive Surgery, vol. 126, no. 6, pp. 1978-1987, 2010.

[23] E. M. Genden, R. Park, C. Smith, and T. Kotz, "The role of reconstruction for transoral robotic pharyngectomy and concomitant neck dissection," Archives of Otolaryngology-Head and Neck Surgery, vol. 137, no. 2, pp. 151-156, 2011.

[24] T. A. Ghanem, "Transoral robotic-assisted microvascular reconstruction of the oropharynx," Laryngoscope, vol. 121, no. 3, pp. 580-582, 2011.

[25] E. S. Garfein, P. J. Greaney Jr, B. Easterlin, B. Schiff, and R. V. Smith, "Transoral robotic reconstructive surgery reconstruction of a tongue base defect with a radial forearm flap," Plastic and Reconstructive Surgery, vol. 127, no. 6, pp. 2352-2354, 2011.

[26] N. R. Dean, E. L. Rosenthal, W. R. Carroll et al., "Roboticassisted surgery for primary or recurrent oropharyngeal carcinoma," Archives of Otolaryngology-Head and Neck Surgery, vol. 136, no. 4, pp. 380-384, 2010.

[27] Y. M. Park, J. G. Lee, W. S. Lee, E. C. Choi, S. M. Chung, and S. H. Kim, "Feasibility of transoral lateral oropharyngectomy using a robotic surgical system for tonsillar cancer," Oral Oncology, vol. 45, no. 8, pp. e62-e66, 2009.

[28] G. S. Weinstein, B. W. O’Malley, M. A. Cohen, and H. Quon, "Transoral robotic surgery for advanced oropharyngeal carcinoma," Archives of Otolaryngology-Head and Neck Surgery, vol. 136, no. 11, pp. 1079-1085, 2010.

[29] H. N. White, E. J. Moore, E. L. Rosenthal et al., “Transoral robotic-assisted surgery for head and neck squamous cell carcinoma: one- and 2-year survival analysis," Archives of Otolaryngology-Head and Neck Surgery, vol. 136, no. 12, pp. 12481252, 2010.

[30] W. Steiner, O. Fierek, P. Ambrosch, C. P. Hommerich, and M. Kron, "Transoral laser microsurgery for squamous cell carcinoma of the base of the tongue," Archives of OtolaryngologyHead and Neck Surgery, vol. 129, no. 1, pp. 36-43, 2003.

[31] B. H. Haughey, M. L. Hinni, J. R. Salassa et al., "Transoral laser microsurgery as primary treatment for advanced-stage oropharyngeal cancer: a united states multicenter study," Head and Neck, vol. 33, no. 12, pp. 1683-1694, 2011.

[32] D. G. Grant, M. L. Hinni, J. R. Salassa, W. C. Perry, R. E. Hayden, and J. D. Casler, "Oropharyngeal cancer: a case for single modality treatment with transoral laser microsurgery," Archives of Otolaryngology-Head and Neck Surgery, vol. 135, no. 12, pp. 1225-1230, 2009.

[33] T. A. Iseli, B. D. Kulbersh, C. E. Iseli, W. R. Carroll, E. L. Rosenthal, and J. S. Magnuson, "Functional outcomes after transoral robotic surgery for head and neck cancer," OtolaryngologyHead and Neck Surgery, vol. 141, no. 2, pp. 166-171, 2009.

[34] W. Li, C. H. Thompson, C. J. O’Brien et al., "Human papillomavirus positivity predicts favourable outcome for squamous carcinoma of the tonsil," International Journal of Cancer, vol. 106, no. 4, pp. 553-558, 2003.

[35] L. Licitra, F. Perrone, P. Bossi et al., "High-risk human papillomavirus affects prognosis in patients with surgically treated oropharyngeal squamous cell carcinoma," Journal of Clinical Oncology, vol. 24, no. 36, pp. 5630-5636, 2006.

[36] H. Mellin, S. Friesland, R. Lewensohn, T. Dalianis, and E. Munck-Wikland, "Human papilloma virus (HPV) DNA in tonsillar cancer: clinical correlates, risk of relapse, and survival," International Journal of Cancer, vol. 89, no. 3, pp. 300304, 2000 .
[37] K. K. Ang, J. Harris, R. Wheeler et al., "Human papillomavirus and survival of patients with oropharyngeal cancer," New England Journal of Medicine, vol. 363, no. 1, pp. 24-35, 2010.

[38] A. C. Nichols, D. M. Finkelstein, W. C. Faquin et al., "Bcl2 and human papilloma virus 16 as predictors of outcome following concurrent chemoradiation for advanced oropharyngeal cancer," Clinical Cancer Research, vol. 16, no. 7, pp. 2138-2146, 2010.

[39] L. B. Harrison, M. J. Zelefsky, J. G. Armstrong, E. Carper, J. J. Gaynor, and R. B. Sessions, "Performance status after treatment for squamous cell cancer of the base of tonguea comparison of primary radiation therapy versus primary surgery," International Journal of Radiation Oncology Biology Physics, vol. 30, no. 4, pp. 953-957, 1994.

[40] D. A. Fein, W. R. Lee, W. R. Amos et al., "Oropharyngeal carcinoma treated with radiotherapy: a 30-year experience," International Journal of Radiation Oncology Biology Physics, vol. 34, no. 2, pp. 289-296, 1996.

[41] J. T. Parsons, W. M. Mendenhall, S. P. Stringer et al., "Squamous cell carcinoma of the oropharynx: surgery, radiation therapy, or both," Cancer, vol. 94, no. 11, pp. 2967-2980, 2002.

[42] J. Staffurth8 and Radiotherapy Development Board, "A review of the clinical evidence for intensity-modulated radiotherapy," Clinical Oncology, vol. 22, no. 8, pp. 643-657, 2010.

[43] P. Blanchard, B. Baujat, V. Holostenco et al., "Meta-analysis of chemotherapy in head and neck cancer (MACH-NC): a comprehensive analysis by tumour site," Radiotherapy and Oncology, vol. 100, no. 1, pp. 33-40, 2011.

[44] J. Bourhis, J. Overgaard, H. Audry et al., "Hyperfractionated or accelerated radiotherapy in head and neck cancer: a metaanalysis," The Lancet, vol. 368, no. 9538, pp. 843-854, 2006.

[45] M. Machtay, J. Moughan, A. Trotti et al., "Factors associated with severe late toxicity after concurrent chemoradiation for locally advanced head and neck cancer: an RTOG analysis," Journal of Clinical Oncology, vol. 26, no. 21, pp. 3582-3589, 2008.

[46] J. J. Caudell, P. E. Schaner, R. F. Meredith et al., "Factors Associated With Long-Term Dysphagia After Definitive Radiotherapy for Locally Advanced Head-and-Neck Cancer," International Journal of Radiation Oncology Biology Physics, vol. 73, no. 2, pp. 410-415, 2009.

[47] J. A. Bonner, P. M. Harari, J. Giralt et al., "Radiotherapy plus cetuximab for squamous-cell carcinoma of the head and neck," New England Journal of Medicine, vol. 354, no. 6, pp. 567-578, 2006.

[48] F. C. Holsinger, A. J. McWhorter, M. Ménard, D. Garcia, and O. Laccourreye, "Transoral lateral oropharyngectomy for squamous cell carcinoma of the tonsillar region: I. Technique, complications, and functional results," Archives of Otolaryngology-Head and Neck Surgery, vol. 131, no. 7, pp. 583-591, 2005.

[49] O. Laccourreye, S. Hans, M. Ménard, D. Garcia, D. Brasnu, and F. C. Holsinger, "Transoral lateral oropharyngectomy for squamous cell carcinoma of the tonsillar region: II. An analysis of the incidence, related variables, and consequences of local recurrence," Archives of Otolaryngology-Head and Neck Surgery, vol. 131, no. 7, pp. 592-599, 2005.

[50] D. K. Henstrom, E. J. Moore, K. D. Olsen, J. L. Kasperbauer, and M. E. McGree, "Transoral resection for squamous cell carcinoma of the base of the tongue," Archives of OtolaryngologyHead and Neck Surgery, vol. 135, no. 12, pp. 1231-1238, 2009.

[51] J. T. Rich, J. Liu, and B. H. Haughey, "Swallowing function after transoral laser microsurgery (TLM) \pm adjuvant therapy 
for advanced-stage oropharyngeal cancer," Laryngoscope, vol. 121, no. 11, pp. 2381-2390, 2011.

[52] J. T. Rich, S. Milov, J. S. Lewis, W. L. Thorstad, D. R. Adkins, and B. H. Haughey, "Transoral laser microsurgery (TLM) \pm adjuvant therapy for advanced stage oropharyngeal Cancer: outcomes and prognostic factors," Laryngoscope, vol. 119, no. 9, pp. 1709-1719, 2009.

[53] G. S. Weinstein, H. Quon, B. W. O’Malley, G. G. Kim, and M. A. Cohen, "Selective neck dissection and deintensified postoperative radiation and chemotherapy for oropharyngeal cancer: a subset analysis of the University of Pennsylvania transoral robotic surgery trial," Laryngoscope, vol. 120, no. 9, pp. 1749-1755, 2010.

[54] M. Moncrieff, J. Sandilla, J. Clark et al., "Outcomes of Primary surgical treatment of T1 and T2 carcinomas of the oropharynx," Laryngoscope, vol. 119, no. 2, pp. 307-311, 2009.

[55] R. R. Walvekar, R. J. Li, W. E. Gooding et al., "Role of surgery in limited (T1-2, N0-1) cancers of the oropharynx," Laryngoscope, vol. 118, no. 12, pp. 2129-2134, 2008.

[56] F. F. de Arruda, D. R. Puri, J. Zhung et al., "Intensitymodulated radiation therapy for the treatment of oropharyngeal carcinoma: the memorial sloan-kettering cancer center experience," International Journal of Radiation Oncology Biology Physics, vol. 64, no. 2, pp. 363-373, 2006.

[57] K. E. Rusthoven, D. Raben, A. Ballonoff, M. Kane, J. I. Song, and C. Chen, "Effect of radiation techniques in treatment of oropharynx cancer," Laryngoscope, vol. 118, no. 4, pp. 635639, 2008.

[58] K. Huang, P. Xia, C. Chuang et al., "Intensity-modulated chemoradiation for treatment of stage III and IV oropharyngeal carcinoma: the university of California-San Francisco experience," Cancer, vol. 113, no. 3, pp. 497-507, 2008.

[59] J. D. Lawson, K. Otto, A. Chen, D. M. Shin, L. Davis, and P. A. S. Johnstone, "Concurrent platinum-based chemotherapy and simultaneous modulated accelerated radiation therapy for locally advanced squamous cell carcinoma of the tongue base," Head and Neck, vol. 30, no. 3, pp. 327-335, 2008.

[60] P. McCulloch, D. G. Altman, W. B. Campbell et al., "No surgical innovation without evaluation: the IDEAL recommendations," The Lancet, vol. 374, no. 9695, pp. 1105-1112, 2009.

[61] N. Agrawal, M. J. Frederick, C. R. Pickering et al., "Exome sequencing of head and neck squamous cell carcinoma reveals inactivating mutations in NOTCH1," Science, vol. 333, no. 6046, pp. 1154-1157, 2011.

[62] N. Stransky, A. M. Egloff, A. D. Tward et al., "The mutational landscape of head and neck squamous cell carcinoma," Science, vol. 333, no. 6046, pp. 1157-1160, 2011. 


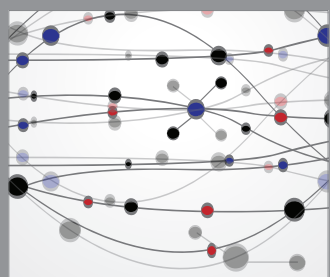

The Scientific World Journal
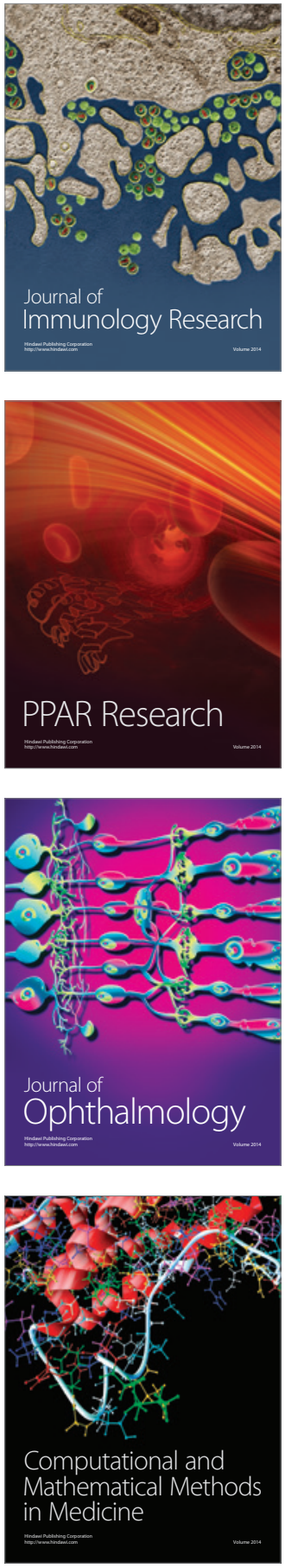

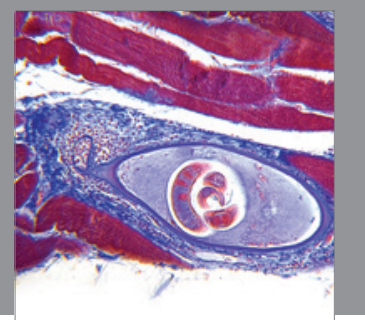

Gastroenterology

Research and Practice
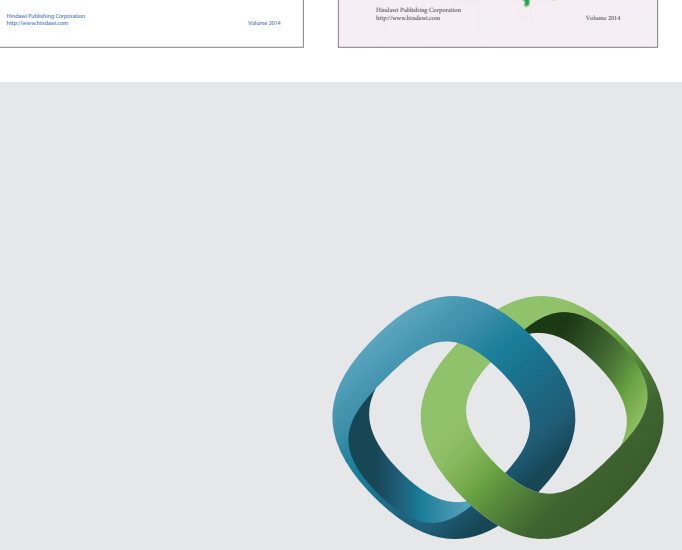

\section{Hindawi}

Submit your manuscripts at

http://www.hindawi.com
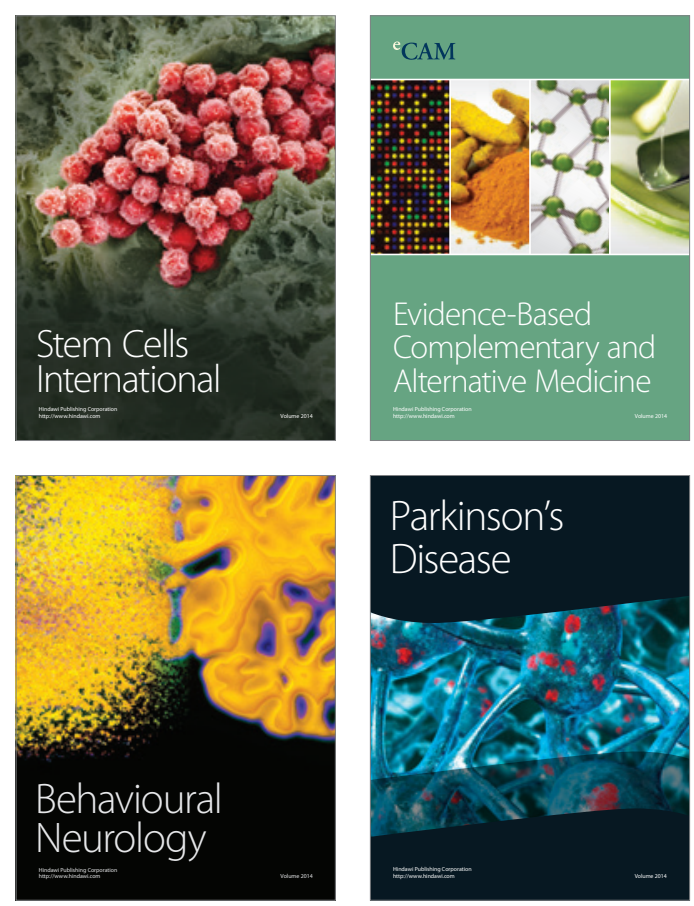

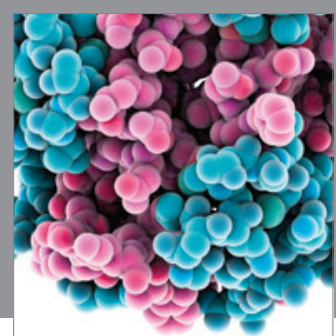

Journal of
Diabetes Research

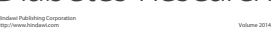

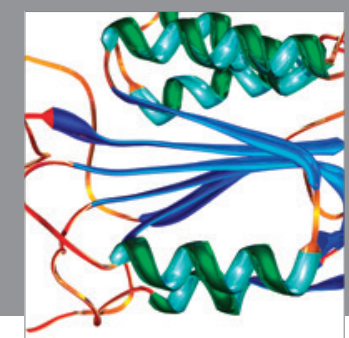

Disease Markers
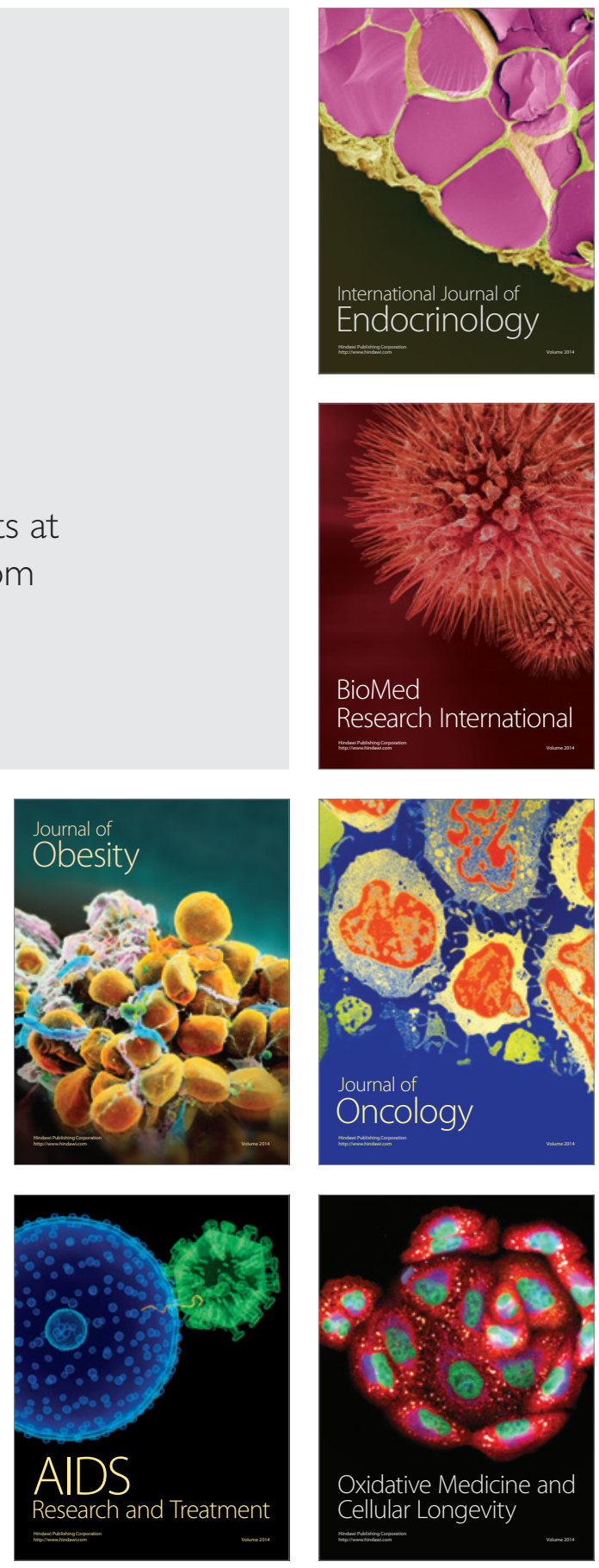